Carter, J. A., and Pritchard, D. (2015) Knowledge-how and cognitive achievement. Philosophy and Phenomenological Research, 91(1), pp. 181-199.

There may be differences between this version and the published version. You are advised to consult the publisher's version if you wish to cite from it.

This is the peer reviewed version of the following article: Carter, J. A., and Pritchard, D. (2015) Knowledge-how and cognitive achievement. Philosophy and Phenomenological Research, 91(1), pp. 181-199, which has been published in final form at http://dx.doi.org/10.1111/phpr.12094. This article may be used for noncommercial purposes in accordance with Wiley Terms and Conditions for SelfArchiving.

http://eprints.gla.ac.uk/132379/

Deposited on: 6 December 2016

Enlighten - Research publications by members of the University of Glasgow http://eprints.gla.ac.uk 
Forthcoming in Philosophy and Phenomenological Research

\title{
KNOWLEDGE-HOW AND COGNITIVE ACHIEVEMENT
}

\author{
J. Adam Carter \& Duncan Pritchard \\ University of Edinburgh
}

\begin{abstract}
According to reductive intellectualism, knowledge-how just is a kind of propositional knowledge (e.g., Stanley \& Williamson 2001; Stanley 2011a, 2011b; Brogaard 2008, 2009, 2011). This proposal has proved controversial because knowledgehow and propositional knowledge do not seem to share the same epistemic properties, particularly with regard to epistemic luck. Here we aim to move the argument forward by offering a positive account of knowledge-how. In particular, we propose a new kind of anti-intellectualism. Unlike neo-Rylean anti-intellectualist views, according to which the possession of knowledge-how is just a matter of possessing certain abilities, we submit that knowledge-how is a particular kind of cognitive achievement attained just when cognitive ability is connected in the right way with successful performance.
\end{abstract}

\section{INTRODUCTION}

Reductive intellectualists about knowledge-how insist that knowing how to do something is just a matter of knowing some fact; knowledge-how just is knowledge-that. ${ }^{1}$ A popular and influential way to make the case for reductive intellectualism is via linguistic argument (Stanley \& Williamson 2001; Stanley 2011a, 2011b; Brogaard 2008, 2009, 2011). This line of argument often goes hand-in-hand with a second dialectical strategy, which is (roughly) to establish that knowledge-wh (e.g., knowledge-where, knowledge-what, knowledge-which) is a kind of knowledgethat, and then further show that the linguistic properties of knowledge-how line up with those of knowledge-wh. $^{2}$

Of course, it is incumbent on the reductive intellectualist to maintain that knowledgehow and knowledge-that must not come apart, and this burden is not limited to just linguistic properties of knowledge-how and knowledge-that ascriptions. Epistemic properties are also fair game, a point that reductive intellectualists grant (e.g., Stanley 2011b, 215). We have argued 
elsewhere (contra reductive intellectualism) that knowledge-how is not knowledge-that, because knowledge-how and knowledge-that differ in their resilience to a certain variety of knowledgeundermining epistemic luck-vir, environmental epistemic luck. ${ }^{3}$ We shall not rehearse these arguments here. Rather, we want to move the argument past our negative case against reductive intellectualism by proposing a positive anti-intellectualist account of knowledge-how. In particular, we will be arguing that knowledge-how is a kind of cognitive achievement. The variety of anti-intellectualism we propose, however, parts ways with neo-Rylean anti-intellectualism in that we reject the view that one knows how to $\varphi$ just in case one possesses the ability to $\varphi$.

The structure of the paper is as follows. In $\$ 1$, we show that cognitive achievement and knowledge-that come apart in both directions. In particular, we argue that cases involving environmental luck can feature cognitive achievements even though knowledge-that is absent. Furthermore, we argue that simple testimony cases can feature knowledge-that even though cognitive achievement is absent. In $\$ \$ 2-3$, we show that states that involve cognitive achievement (e.g., understanding-why) come apart from knowledge-that in precisely those cases where knowledge-that and cognitive achievement come apart, and further, that knowledge-wh lines up with knowledge-that, and not with cognitive achievement. Finally, in $\$ 4$ we employ the kinds of cases which demonstrate that cognitive achievement and knowledge-that come apart to show that knowledge-how lines up squarely with understanding-why (and more generally with cognitive achievements), but not with knowledge-wh and knowledge-that. Furthermore, we propose a positive characterisation of a cognitive-achievement-based account of knowledgehow, according to which: If one successfully Fs because of one's ability (vis-à-vis F), then one knows how to $\mathrm{F}$, and conversely, that if one knows how to $\mathrm{F}$, then one is positioned to successfully F because of one's ability (vis-à-vis F).

\section{COGNITIVE ACHIEVEMENT AND KNOWLEDGE-THAT}

One influential proposal in contemporary epistemology—advanced as part of a particularly ambitious version of virtue epistemology — is the idea that we should conceive of knowledge-that as a specifically cognitive kind of achievement. 'Achievement' is here understood in a very inclusive sense as covering any kind of success which is because of the exercise of one's (relevant) ability. So construed, certain kinds of successes fail to count as genuine achievements. A success - hitting the bull's-eye with one's bolt, say — is not an achievement if it is due to blind luck and not because of ability. Moreover, even if there is genuine ability on display-if, say, one 
skilfully fired the bolt - this won't suffice for an achievement if there is not the right kind of relationship between the success and the ability. For suppose one skilfully fires a bolt at a target, and one hits the bull's-eye of that target, but that luck intervenes along the way-say, a gust of wind blows the bolt off course, and another gust of wind fortuitously blows it back on course again. Here we have success and the relevant ability on display, but due to the intervening luck at issue there is not the right kind of relationship between them to suffice for an achievement. That is, the success is not because of ability, but is rather due to the fortuitous luck involved. ${ }^{4}$

As a rough account of achievements, this proposal is fairly plausible. It doesn't quite match up to the ordinary language notion of an achievement in that it is too inclusive - raising one's hand could constitute an achievement on this view, even though ordinary language would dictate otherwise — but we are at least plausibly capturing here a general phenomenon of which the ordinary language notion is a more demanding sub-class. Of course, one would like to be told how best to unpack the 'because of relation, though this is not an issue that we can usefully explore here. There is thus another sense in which this proposal is rough, in that it is at present underdescribed. ${ }^{5}$

In any case, with this rough account of achievements in play one can see the attraction in regarding knowledge-that as a cognitive kind of achievement. That is, knowledge-that is cognitive success (i.e., true belief) that is because of the exercise of (the relevant) cognitive ability. On this view there is a simple explanation of why knowledge-that is lacking in the Gettier-style cases, in that while there is cognitive success and the relevant cognitive ability on display, the former is not because of the latter, but rather due to happenstance. Given that virtue epistemology is typically characterised by its insistence that cognitive abilities—where this is a category broad enough to include both our cognitive faculties and our intellectual virtues — should take centre-stage within epistemology, we thus get a distinctively virtue-theoretic account of knowledge-that. ${ }^{6}$ Call such a proposal robust virtue epistemology. ${ }^{7}$

Despite the surface attraction of robust virtue epistemology, it does face some fairly formidable problems. In particular, there are cases which seem to demonstrate that as an account of knowledge-that it is sometimes too strong and sometimes too weak, a combination which threatens to tear the view asunder (in that whatever the proponent of robust virtue epistemology does to deal with the one kind of problem will almost certainly make it harder for them to deal with the other kind of problem). Interestingly for our purposes, the case for thinking that robust virtue epistemology is too strong an account of knowledge-that turns on the distinction between environmental luck and intervening luck. 
Consider again the case described above in support of the idea that achievements are successes that are because of ability, which involved two gusts of wind which fortuitously cancelled each other out. This is clearly intervening luck, in that luck intervenes between the manifestation of ability (the skilful firing of the bolt) and the relevant success (the hitting of the target), such that the success could so very easily have been a failure. ${ }^{8}$ Intervening luck is not compatible with genuine achievements, as we noted above. Since most Gettier-style cases involve intervening luck, ${ }^{9}$ it is thus no surprise that robust virtue epistemology can comfortably handle such cases. The farmer who thinks she sees a sheep and so believes that there is a sheep in the field, but who is in fact looking merely at a sheep-shaped object, is not cognitively successful because of her cognitive ability, but rather because of the happenstance that a sheep is hidden from view behind the sheep-shaped object that she is looking at. ${ }^{10}$ Intervening luck is incompatible with achievements, and hence cognitive achievements (i.e., cognitive successes that are because of cognitive ability), which given that knowledge-that is also incompatible with intervening epistemic luck is thus far just the right result as far as robust virtue epistemology is concerned.

But consider now the relationship between achievements, and thus cognitive achievements, and environmental luck. Environmental luck concerns cases where nothing intervenes between the manifestation of ability and the relevant success, but where that success is nonetheless lucky in virtue of some feature of the subject's environment. ${ }^{11}$ Imagine an archer who skilfully takes aim and who hits the bulls-eye without anything getting in the way betwixt shot and target. There is thus no intervening luck in play here. But suppose that there is environmental luck in play. Imagine, for example, that our archer's shot could so very easily have been affected by freak gusts of wind but in fact wasn't—she just happened to fire at the precise moment to avoid the freak gusts, which would have otherwise affected her shot. The archer's success is thus lucky, in that it is a success that could so very easily have been a failure, but where this luck is of the environmental rather than the intervening variety. Here is the crux: Is this archer's success any less of an achievement in virtue of being subject to specifically environmental luck?

We claim that the natural answer to this question is 'no'. While intervening luck can undermine a genuine achievement, a success is no less because of ability if there is environmental luck in play. After all, although our archer's success could so very easily have been a failure, the fact remains that her success is entirely down to her agency, in that what could have so very easily have intervened didn't in fact intervene. That is, her success is clearly because of her ability, even while being lucky. Indeed, we submit that it is no less of an achievement to produce 
a success that is because of ability which is lucky in this way than it is to produce a success that is because of ability and which is in addition not subject to environmental luck. ${ }^{12}$

What goes for achievements more generally also applies to specifically cognitive achievements. In particular, in cases of environmental epistemic luck an agent's cognitive success is no less because of her cognitive ability than if the epistemic luck had been absent, and hence it qualifies as a cognitive achievement. But given the environmental epistemic luck in play the cognitive success is nonetheless lucky, and hence it follows that it is not a case of knowledgethat. More precisely, knowledge excludes luck at least to this extent: when one knows, then one's cognitive success cannot, given how it was formed, have easily been a cognitive failure. ${ }^{13}$

In order to see this, consider again the case we just offered to illustrate intervening epistemic luck. This involved a farmer getting a good view of a sheep-shaped object in suitable cognitive conditions and forming the true belief on this basis that there is a sheep in the field. Suppose now we vary this case so that it explicitly involves environmental epistemic luck. Imagine, for example, that the farmer really was looking at a genuine sheep, it was just that she was in an environment in which she could so very easily have been deceived by sheep-shaped objects into forming a false belief in this regard. In both formulations of the case, the farmer's cognitive success is lucky, in that it is a cognitive success that could so easily have been a cognitive failure. This is why we judge both cases to not be instances of knowledge-that.

It is not in question that in the first case the farmer's cognitive success does not constitute an cognitive achievement, since by anyone's lights it is not a cognitive success that is because of her cognitive ability, as opposed to being due to the good fortune of there being a sheep hidden from view behind the sheep-shaped object that she is looking at. But what about the second case? In particular, given that the farmer was not in fact deceived, and is in fact forming her belief about whether there is a sheep in the field by getting to see a sheep in good cognitive conditions, why would we deny that this constitutes a genuine cognitive achievement? Put another way, even despite the environmental epistemic luck in play, isn't her cognitive success because of the exercise of her cognitive ability?

Compare the archer case involving environmental epistemic luck, describe above. We noted there that hitting the bull's-eye through ability in an environment in which one could so very easily have been unsuccessful, but where one was not in fact unduly influenced by any external factors, does not prevent one's success from being because of one's agency, and so counting as an achievement. But what is different about the epistemic variant of this scenario just offered? Accordingly, by parity of reasoning, what we say about achievements more 
generally should apply to specifically cognitive achievements, with the implication that they are compatible, unlike propositional knowledge, with environmental epistemic luck.

The upshot of the foregoing is that the theory of knowledge-that offered by robust virtue epistemology is too weak, in that it is committed to treating lucky achievements as knowledge, even though knowledge excludes luck of this variety. ${ }^{14}$ But there is also a second class of cases which show that this theory of knowledge-that is also too strong, in that it is committed to denying knowledge-that to agents in scenarios where, very plausibly, such knowledge is possessed.

The best way of bringing this point into sharp relief is by considering cases of testimonial knowledge-that which has been gained in conditions which are epistemically very friendly. So, for example, consider an agent finding out directions in an unfamiliar city by consulting an informant, where informants in these parts are, about these matters anyway, uniformly reliable, helpful, and so forth. In order for this to constitute a genuine case of knowledge-that, it is of course important that our hero should exercise some relevant cognitive ability in forming her testimonial belief. For example, it had better not be the case that she would ask anyone (i.e., she had better be sensitive to indications that someone is not a good informant about this subject matter, such as that they are clearly tourists), and it had better not be the case that she would believe anything that she is told (i.e., no matter how ridiculous it is). Crucially, however, at least on standard views in the epistemology of testimony, the exercise of very little cognitive ability can be enough for a subject to count as having testimonial knowledge-that in the right conditions. In particular, in favourable epistemic conditions, it is possible for agents to gain testimonial knowledge-that while to a large extent simply trusting their informant.

Here is the crux. Would our agent's cognitive success count as being because of the exercise of her cognitive ability? We suggest not. For while she has manifested some relevant cognitive ability, her cognitive success seems to be more down to the informant than due to her, in that her own cognitive abilities are playing a very minor role in generating this cognitive success. But this means that there is sometimes less to knowledge-that than cognitive achievement. $^{15}$

Knowledge-that thus comes apart from cognitive achievement in both directions, in that there are cases of the former which aren't cases of the latter, and cases of the latter which aren't cases of the former. Reflecting on the examples we have looked at, the moral is that while the notion of a cognitive achievement picks out a particular kind of success which is attributable to one's cognitive agency, the relationship between knowledge-that and cognitive agency is more complex. For sure, knowledge-that requires the manifestation of relevant cognitive ability. Even 
in the testimonial case just considered there was relevant cognitive ability on display. But we have also seen that knowledge-that can be dependent on factors outwith the subject's cognitive agency too, in both a positive and negative fashion. That is, there are cases where very little cognitive agency is on display but which count as knowledge-that in virtue of the epistemically positive nature of the environment (e.g., the testimonial case just considered). And there are also cases in which a great deal of cognitive agency is on display -i.e., a degree of cognitive agency which would ordinarily suffice for knowledge-that — but which don't count as knowledge-that due to the epistemically negative nature of the environment (e.g., the cases of environmental epistemic luck considered earlier). ${ }^{16}$

\section{UNDERSTANDING-WHY, KNOWLEDGE-THAT AND COGNITIVE ACHIEVEMENT}

Where epistemic states come apart from knowledge-that in exactly those cases where (as we saw in \$1) cognitive achievement comes apart from knowledge-that such that these states exhibit the same relationship to epistemic luck as cognitive achievements - there is a reasonable prima facie case for supposing that these epistemic states involve cognitive achievement. In order to see this point in action, consider the epistemic state of understanding-why. As we will see, understanding-why is (just like cognitive achievement and knowledge-that) incompatible with Gettier-style (intervening) epistemic luck, even though it is nonetheless compatible with environmental epistemic luck (just like cognitive achievement but unlike knowledge-that). Moreover, it is not the kind of epistemic state that can largely be acquired through trust of another (just like cognitive achievement but unlike knowledge-that).

Consider a subject—let's call him 'Campbell'—who comes home to discover that his house has burned down, and asks someone what caused this to happen. In the first version of the case, suppose (in a typical Gettier-style fashion) that Campbell asks a fake fire officer in fancy dress why his house burnt down and is by happenstance provided with a correct explanation (that it was due to faulty wiring, say). In the second version of the case, in contrast, hold fixed that the explanation given is correct but now suppose the informant is in fact a genuine fire officer, albeit surrounded by fake fire officers in fancy dress (who Campbell could have just as easily asked as the genuine fire officer, and who would have led him astray).

It's hard to deny that the first kind of case looks like an obvious kind of 'Gettier' case for understanding-why, in that the intervening epistemic luck at play prevents Campbell from 
understanding-why his house burnt down. Given the epistemic luck involved, Campbell doesn't gain knowledge-that in this case either. But, interestingly, the second version of the case seems to elicit a different response. Though the environmental epistemic luck at play in this second version of the case would be enough to undermine propositional knowledge that the house burnt down, the same doesn't hold for understanding-why. Indeed, that Campbell could so easily been given the wrong explanation seems perfectly compatible with him having gained an understanding of why his burned down in this case. ${ }^{17}$ But if this is right, then notice that understanding-why and cognitive achievement align in that they are both incompatible with Gettier-style (intervening) epistemic luck while nonetheless being (unlike knowledge-that) compatible with environmental epistemic luck.

Now for the other side of the coin: notice that understanding-why also appears to be lacking in just the kind of testimonial cases in which agents acquire testimonial knowledge-that but don't exhibit the degree of cognitive agency which would suffice for a cognitive achievement. Consider again the case just offered above of Campbell discovering what caused his house to burn down. This time, however, let us stipulate that there is no epistemic 'funny business' going on, in that there is neither intervening nor environmental epistemic luck in play. Instead, he simply acquires his knowledge-that the house burned down due to faulty wiring from speaking to a genuine fire officer.

Presumably, Campbell has a good grasp of how faulty wiring might cause a house fire, one that is sufficient for him to be credited not just with knowledge-that, but also with understanding-why. But imagine that he passes on his knowledge of what caused the house fire to his young son, and that while the son knows what faulty wiring is, he lacks a solid conception of how faulty wiring might cause a house fire. Campbell's son can come to know that the house burned down because of faulty writing by receiving this information from his father, at least so long as he is capable of being reasonably circumspect about who he receives testimony from and what he believes on the basis of testimony (i.e., such that he doesn't believe everyone about everything). Of course, he will be to a large extent trusting his father's word in this regard, but in these circumstances, and about a subject matter like this, such trust seems entirely compatible with the acquisition of testimonial knowledge. But given that Campbell's son lacks a solid grip on how cause and effect might be related, can he be rightly said to understand why his house burned down? We suggest not.

Knowledge-that and understanding-why thus come apart in both directions. Moreover, the cases where knowledge-that and cognitive achievement come apart seem to be just the same kinds of cases where knowledge-that and understanding-why come apart. There may be a good 
reason for this, in that there is at least a strong prima facie case for thinking that understandingwhy is a kind of cognitive achievement. Indeed, understanding-why seems to have the close ties with cognitive agency which we saw was not the case with propositional knowledge, in that knowledge-that is both positively and negatively dependent on factors significantly outwith the subject's cognitive agency. That is, when one has understanding-why, it is always the case that one's cognitive success is attributable to one's cognitive agency (in the sense that the cognitive success is because of one's exercise of relevant cognitive ability). That would explain why understanding-why is compatible with environmental epistemic luck, and also why knowledgethat, where it falls short of cognitive achievement (as in the testimonial cases we have been looking at), does not suffice for understanding-why. ${ }^{18}$

\section{KNOWLEDGE-WH, KNOWLEDGE-THAT AND COGNITIVE ACHIEVEMENT}

Interestingly, while it is plausible to contend that understanding-why involves cognitive achievement, it seems pretty clear that knowledge-wh is not a cognitive achievement. For one thing, consider that knowledge-wh seems (unlike cognitive achievements, and thus understanding-why) to be incompatible with environmental epistemic luck in a way akin to knowledge-that. For another, this is the kind of epistemic state that can be gained by for the most part trusting the word of another (like knowledge-that, but unlike cognitive achievements, and thus understanding-why). In order to see these points, consider knowledge-why.

We take it as obvious that Campbell can't come to know why his house burned down by talking to a fake fire officer who happens to offer the correct explanation. Knowledge-why is thus incompatible with intervening epistemic luck (just like knowledge-that and cognitive achievements). Can Campbell gain knowledge-why where the epistemic luck in play is environmental? That is, can Campbell come to know why his house burned down by gaining his belief about why his house burnt down by happening to consult a genuine fire officer surrounded by a group of fakes who would have misled him (such that his true belief is due to luck)? We suggest not: if one knows why such-and-such is the case, then one's knowledge cannot be subject to luck in this way. ${ }^{19}$ Genuine knowledge-why-like knowledge-that, but unlike cognitive achievements and thus understanding-why precludes the possibility that one could easily be wrong.

What about cases where knowledge-wh falls short of cognitive achievement? Does Campbell's son (who, recall from $₫ 2$, failed to understand-why his house burned down) know 
why his house burned down? We maintain that he does. Indeed, it would be odd to attribute to him propositional knowledge that he knows that his house burned down because of faulty wiring and yet deny that he knows why his house burned down. If asked why his house burned down, he could give the correct answer, and do so because he formed his belief by being informed by an authoritative source. What could possibly prevent him from having knowledge-why in this case? Again, then, we find that knowledge-wh is lining up with knowledge-that, unlike understanding-why, which is lining up with cognitive achievement.

\section{KNOWLEDGE-HOW AND COGNITIVE ACHIEVEMENT}

We've argued elsewhere that knowledge-how is (unlike knowledge-that) compatible with knowledge-undermining epistemic luck. ${ }^{20}$ While there's much to be said for this claim, a simple way to see why it's so is to consider a kind of twist on the LUCKY LIGHT BULB case, as offered in recent work by Yuri Cath (2011). Here is the case:

LUCKY LIGHT BULB: Charlie wants to learn how to change a light bulb, but he knows almost nothing about light fixtures or bulbs. So he consults The Idiot's Guide to Everyday Jobs. Inside, Charlie finds an accurate set of instructions describing a light fixture and bulb, and the way to change a bulb. Charlie grasps these instructions perfectly. And there is a way, call it ' $w_{1}$ ', such that Charlie now believes that $\mathrm{w}_{1}$ is a way for him to change a light bulb, namely, the way described in the book. However, unbeknownst to Charlie, he is extremely lucky to have read these instructions. For the disgruntled author of The Idiot's Guide filled her book with misleading instructions. Under every entry she misdescribed the objects involved in that job, and described a series of actions that would not constitute a way to do the job at all. However, at the printers, a computer error caused the text under the entry for 'Changing a Light Bulb', in just one copy of the book, to be randomly replaced by new text. By incredible coincidence, this new text provided the clear and accurate set of instructions that Charlie would later consult. (Cath 2011, \$1)

Cath contends that Charlie knows how to change a light bulb, but that he does not know that $\mathrm{w}_{1}$ is a way for him to change a light bulb. Cath thus takes the moral of this case to be that knowledge-how comes apart from knowledge-that. But this conclusion is controversial. ${ }^{21}$

LUCKY LIGHT BULB clearly involves intervening epistemic luck. But imagine a variation of this case which concerns instead environmental epistemic luck. Suppose, for example, that Charlie is consulting a genuine, authoritative light bulb changing guide, which just happens to be surrounded by fakes, and had he opted to consult one of the fakes, he would have gained incorrect instructions. Does Charlie know how to change a light bulb? Whereas we would grant that it's not obvious that Charlie has this knowledge-how in the original case (where the fake guide is consulted), ${ }^{22}$ the intuition changes dramatically when the luck at play is environmental. In particular, we suggest that given that Charlie has gained his belief from a 
genuine authoritative light bulb changing guide, then he knows how to change to light bulb. ${ }^{23}$ In this respect, then, notice that knowledge-how is aligning with cognitive achievement (and thus understanding-why), and coming apart from knowledge-wh and knowledge-that.

It is natural then to ask whether knowledge-how is present in cases of knowledge-that which fall short of a cognitive achievement. Going back to the LUCKY LIGHT BULB case, suppose that Charlie finds out how to change a light bulb by receiving this information from what he knows to be a reliable information source (and that there is, in addition, nothing epistemically amiss in his acquisition of this information), and that Charlie passes this information onto his young son. Let us stipulate that Charlie's son exhibits the same level of cognitive ability as we saw exhibited in the testimonial case considered above. That is, while he wouldn't have asked just anyone or believed just anything that he is told, it is nonetheless the case that for the most part he is merely trusting the word of his father. Nonetheless, his father is indeed authoritative in this regard, and the environment is epistemically friendly in all the relevant respects (in particular, it is not the case, for example, that Charlie's son could so very easily have been deceived by his father).

As we saw above, on standard proposals regarding testimonial knowledge-that, Charlie's son will come to have knowledge-that in this case (i.e., knowledge-that such-and-such is how one goes about changing a bulb). But does he know how to change a light bulb? Sure, he can change a bulb, but there is plausibly more required for knowledge-how than that. What we are after when it comes to know-how is not merely the ability to produce a certain outcome, but rather a particular kind of epistemic relation that the agent exhibits with respect to that outcome. And sure, Charlie knows how to change a light bulb, since he can vouch for the epistemic source of his information. But the key question is whether Charlie's son can come to acquire knowledgehow in this case, given that he is for the most part simply trusting his father's testimony. We suggest not. Indeed, we claim that such cases illustrate the demandingness of knowledge-how, in that it is not sufficient for knowledge-how that one merely has the ability to undertake the target activity. Instead, it is required that one's cognitive success should be appropriately related to one's cognitive ability, such that the former is because of the latter. Where this is not the case, as in the testimonial example involving Charlie's son just considered, then the agent concerned does not qualify for knowledge-how.

If the foregoing is right, then we should think of knowledge-how as a kind of cognitive achievement, and thus group it with understanding-why, in contrast to forms of knowledge-wh which are naturally grouped with propositional knowledge in terms of their relationship to epistemic luck. We hold that the idea that knowledge-how is essentially a kind of cognitive 
achievement has a great deal of plausibility. After all, this is the proposal that knowledge-how is a type of cognitive success that is because of cognitive ability, and that seems just right.

We noted above that knowledge-how is not to be identified with merely the ability to produce a certain outcome, since what we are after is a particular kind of epistemic relation that the agent holds with respect to that outcome. Significantly, this point about how knowledge-how requires more than the mere ability to produce a certain outcome, such that knowledge-how demands the right kind of relationship between cognitive success and cognitive ability, also provides us with the resources for dealing with a certain kind of reservation that might naturally be levelled at the proposal that knowledge-how is a kind of cognitive achievement. The worry is broadly as follows. If one is to reject intellectualism about knowledge-how, then presumably one will opt instead for its competitor proposal and adopt a form of neo-Ryleanism about knowledge-how. But on the anti-intellectualist neo-Rylean view, isn't knowledge-how nothing more than the possession of a certain ability or disposition? But how then can one consistently argue that knowledge-how is a kind of cognitive success which is because of cognitive ability (i.e., a cognitive achievement) and argue that knowledge-how is nothing more than the possession of a certain ability?

We think this potential objection is too quick. Consider, for example, Ted Poston's $(2009,744)$ claim (originally presented as part of an argument that knowledge-how is impervious to Gettier-style cases) that if one can intelligently ${ }^{24}$ and successfully $\mathrm{F}$, then one knows how to F. ${ }^{25}$ This is straightforwardly neo-Rylean because know-how is analysed in terms of the ability or disposition to do something (intelligently and successfully F). As Poston puts it, "If, for instance, Sally intelligently moves this way and that way with the goal of riding a bike and she succeeds then Sally knows how to ride a bike.” (Poston 2009, 744)

If Poston's suggestion is plausible, then a picture emerges for how knowledge-how might be conceived as a kind of cognitive achievement on the neo-Rylean model: we simply amend Poston's account so that the ability and success components can't merely be 'accidentally satisfied' conjunctively; instead, we stipulate that the success element be because of the ability element. This amendment is quite plausible: after all, if Sally succeeds at riding a bike always because of a benevolent demon and never because of her ability (which always ends up disconnected from her success, by the demon), then it seems rather implausible that she knows how to ride a bike (perhaps, we'd say, she never had the chance) ${ }^{26}$ Amended this way, and with the further amendment that we use the term "cognitive ability" as opposed to Poston's more general term “intelligence”, Poston's characterisation of knowledge-how would be: If one successfully Fs because of one's ability (vis-à-vis F), then one knows how to F. If this is right, and 
the converse holds - i.e., that if one knows how to F, then one is positioned to successfully $\mathrm{F}$ because of one's ability (vis-à-vis F) - then we have an account of what it would be for knowledge-how to essentially involve cognitive achievement. ${ }^{27}$ The Sally case suggests that this sort of account has much to recommend it, in that it captures a clear insight about the relationship between ability and success in cases of knowledge-how, a relationship which is best explained by supposing that knowledge-how essentially involves cognitive achievement. What results, then, is a cognitive-achievement account of knowledge-how that is a viable alternative to both intellectualist views (given that knowledge-how and cognitive achievement come apart in both directions), and to neo-Rylean anti-intellectualists accounts according to which knowledgehow is just a matter of possessing certain abilities.

\section{CONCLUSION}

We've argued here that knowledge-how is a kind of cognitive achievement. In doing so, we've strengthened our negative case against intellectualism (defended elsewhere) in the following way: we've shown that cognitive achievement and knowledge-that come apart in both directions, and, further, that knowledge-how essentially involves cognitive achievement. To the extent that knowledge-how involves cognitive achievement, then, we should reject intellectualist proposals which are committed to denying that knowledge-how and knowledge-that will come apart.

But in identifying knowledge-how with a particular kind of cognitive achievement, we've not merely challenged the intellectualist, but at the same time also challenged the traditional neoRylean anti-intellectualist who insists that knowledge-how is just a matter of ability possession. Again, if our argument that knowledge-how is a kind of cognitive achievement is successful, then we have a clear explanation for why the neo-Rylean account should be rejected-namely, because knowledge-how is more demanding, in that it involves (beyond just the possession of certain abilities) that one's successful performance be not merely accidentally a product of such abilities, but rather because of their exercise. We are thus proposing a new kind of antiintellectualism about knowledge-how, and in doing so offering a novel way to avoid some of the most obvious problems for both the most popular varieties of intellectualism and antiintellectualism. ${ }^{28}$ 


\section{REFERENCES}

Axtell, G. (1997). 'Recent Work on Virtue Epistemology', American Philosophical Quarterly 34, 1-26. Bengson, J. \& Moffett, M. (2007). 'Know-How and Concept Possession', Philosophical Studies 136, 31-57.

- (2011a). 'Non-Propositional Intellectualism', Knowing How: Essays on Knowledge, Mind, and Action, (eds.) J. Bengson \& M. Moffett, 161-90, Oxford University Press, Oxford. (2011b). 'Two Conceptions of Mind and Action: Knowing How and the Philosophical Theory of Intelligence', Knowing How: Essays on Knowledge, Mind, and Action, (eds.) J. Bengson \& M. Moffett, 3-58, Oxford University Press, Oxford.

Bengson, J., Moffett, M., \& Wright, J. (2009). 'The Folk on Knowing How', Philosophical Studies $142,24-50$

Brogaard, B. (2008a). 'Attitude Reports: Do you Mind the Gap?', Philosophy Compass 3, 93-118. (2008b). 'Knowledge-The and Propositional Attitude Ascriptions', Grazer Philosophische Studien 77, 147-90.

(2009). 'What Mary Did Yesterday: Reflections on Knowledge-wh', Philosophy and Phenomenological Research 78, 439-67.

(2011). 'Knowledge-How: A Unified Account', Knowing How: Essays on Knowledge, Mind, and Action, (eds.) J. Bengson \& M. Moffett, 136-60, Oxford University Press, Oxford.

Carter, J. A., \& Pritchard, D. H. (2013). 'Knowledge-How and Epistemic Luck', Noûs (Online First, DOI: 10.1111/nous.12054).

Cath, Y. (2011). 'Knowing How Without Knowing That', Knowing How: Essays on Knowledge, Mind and Action, (eds.) J. Bengson \& M. Moffett, 113-35, Oxford University Press, Oxford.

Chisholm, R. (1977). Theory of Knowledge ( ${ }^{\text {nd }}$ Ed.), Prentice-Hall, Englewood Cliffs, NJ.

Gettier, E. (1963). 'Is Justified True Belief Knowledge?' Analysis 23, 121-23.

Greco, J. (2010). Achieving Knowledge: A Virtue-Theoretic Account of Epistemic Normativity, Cambridge University Press, Cambridge.

Grimm, S. (2006). 'Is Understanding a Species of Knowledge?' British Journal for the Philosophy of Science 57, 515-35.

— (Forthcoming). 'Understanding as Knowledge of Causes', Virtue Scientia: Essays in Philosophy of Science and Virtue Epistemology, (ed.) A. Fairweather, Springer, Dordrecht, Holland.

Hetherington, S. (2013). 'There Can Be Lucky Knowledge', Contemporary Debates in Epistemology $\left(2^{\text {nd }}\right.$ Ed.), (eds.) M. Steup \& J. Turri, Blackwell, Oxford.

Kallestrup, J., \& Pritchard, D. H. (2011). 'Virtue Epistemology and Epistemic Twin Earth', European Journal of Philosophy (Online First, DOI: 10.1111/j.1468-0378.2011.00495.x).

— (2012). 'Robust Virtue Epistemology and Epistemic Anti-Individualism', Pacific Philosophical Quarterly 93, 84-103.

- (2013). 'Robust Virtue Epistemology and Epistemic Dependence', Knowledge, Virtue and Action, (eds.) T. Henning \& D. Schweikard, ch. 11, Routledge, London.

Luper, S. (1984). 'The Epistemic Predicament', Australasian Journal of Philosophy 62, 26-50.

- (2003). 'Indiscernability Skepticism', The Skeptics: Contemporary Essays, (ed.) S. Luper, 183202, Ashgate, Aldershot.

Poston, T. (2009). 'Know-How to be Gettiered?', Philosophy and Phenomenological Research 79, 743-7.

Pritchard, D. H. (2002). 'Resurrecting the Moorean Response to the Sceptic', International Journal of Philosophical Studies 10, 283-307.

(2005). Epistemic Luck, Oxford University Press, Oxford.

(2007). 'Anti-Luck Epistemology', Synthese 158, 277-97.

(2009a). 'Apt Performance and Epistemic Value', Philosophical Studies 143, 407-16.

(2009b). Knowledge, Palgrave Macmillan, Basingstoke, UK. 
- (2009c). 'Knowledge, Understanding and Epistemic Value', Epistemology (Royal Institute of Philosophy Lectures), (ed.) A. O’Hear, 19-43, Cambridge University Press, Cambridge.

(2012a). 'Anti-Luck Virtue Epistemology', Journal of Philosophy 109, 247-79.

(2012b). 'In Defence of Modest Anti-Luck Epistemology', The Sensitivity Principle in Epistemology, (eds.) T. Black \& K. Becker, 173-92, Cambridge University Press, Cambridge.

- (2013). 'There Cannot be Lucky Knowledge', Contemporary Debates in Epistemology (2 ${ }^{\text {nd }}$ Ed.), (eds.) M. Steup \&J. Turri, Blackwell, Oxford.

— (Forthcominga). 'Knowledge and Understanding', Virtue Scientia: Essays in Philosophy of Science and Virtue Epistemology, (ed.) A. Fairweather, Springer, Dordrecht, Holland.

- (Forthcomingb). 'The Modal Account of Luck', Metaphilosophy.

Pritchard, D. H., Millar, A., \& Haddock, A. (2010). The Nature and Value of Knowledge: Three Investigations, Oxford University Press, Oxford.

Pritchard, D. H., \& Smith, M. (2004). 'The Psychology and Philosophy of Luck', New Ideas in Psychology 22, 1-28.

Ryle, G. (1971 [1946]). 'Knowing How and Knowing That', reprinted in his Gilbert Ryle: Collected Papers (vol. 2), 212-25, Barnes \& Noble, New York.

- (1949). The Concept of Mind, Chicago University Press, Chicago.

Sainsbury, R. M. (1997). 'Easy Possibilities', Philosophy and Phenomenological Research 57, 907-19.

Sosa, E. (1988). 'Beyond Skepticism, to the Best of Our Knowledge', Mind 97, 153-89.

— (1991). Knowledge in Perspective: Selected Essays in Epistemology, Cambridge University Press, Cambridge.

- (1999). 'How to Defeat Opposition to Moore', Philosophical Perspectives 13, 141-54.

(2007). A Virtue Epistemology: Apt Belief and Reflective Knowledge, Oxford University Press, Oxford.

- (2009). Reflective Knowledge: Apt Belief and Reflective Knowledge, Oxford University Press, Oxford.

Stanley, J. (2011a). 'Knowing (How)', Noûs 45, 207-38.

- (2011b). Know How, Oxford University Press, Oxford.

Stanley, J., \& Williamson, T. (2001). 'Knowing How', Journal of Philosophy 98, 411-44.

Williamson, T. (2000). Knowledge and its Limits, Oxford University Press, Oxford.

Zagzebski, L. (1996). Virtues of the Mind: An Inquiry into the Nature of Virtue and the Ethical Foundations of Knowledge, Cambridge University Press, Cambridge.

- (1999). 'What is Knowledge?', The Blackwell Guide to Epistemology, (eds.) J. Greco \& E. Sosa, 92-116, Blackwell, Oxford. 


\section{NOTES}

1 See Bengson \& Moffett (2011a; 2011b) for a non-reductive version of intellectualism.

2 For the most influential and sustained recent example of this strategy, see Stanley (2011b).

3 See Carter \& Pritchard (2013) for an argument to the effect that environmental epistemic luck, while incompatible with propositional knowledge, is nonetheless compatible with knowledge-how. It is thus concluded, contra the reductive intellectualist, that knowledge-how and knowledge-that come apart.

4 For further discussion of this general notion of an achievement, see Pritchard, Millar \& Haddock (2010, ch. 2).

5 There are two main proposals in the literature: Sosa's (e.g., 2007) disposition manifestation account and Greco's (e.g., 2010) causal explanatory account. In addition, some have argued that the 'because of relation should be treated as an undefinable primitive (e.g., Zagzebski 1999). For further discussion of these different accounts of the 'because of' relation and their relevance to particular renderings of virtue epistemology, see Kallestrup \& Pritchard (2011)

${ }^{6}$ Note that we are using cognitive ability in the way that is common among virtue epistemologists—viz:, to refer to intellectual virtues, broadly construed. Cognitive ability is a term Greco (2010) has popularized in part because it is prima facie compatible with different substantive accounts of intellectual virtues. Here, specifically, we have in mind the debate that persists between virtue reliabilists and virtue responsibilists: whilst virtue reliabilists conceive of intellectual virtues in a way that is akin to reliable faculties (e.g., memory, eyesight) that are appropriately integrated in one's cognitive character, virtue responsibilists view the intellectual virtues as more akin to character traits that an agent can be praiseworthy for acquiring through habituation. At any rate, our use of 'cognitive ability' is not meant to be loaded in favour of either side of this debate, even though cognitive abilities are meant to pick out cognitive dispositions that are more fine-grained than intelligence simpliciter (in contrast to Poston (2009)). For more on the distinction between reliabilist and responsibilist conceptions of virtue epistemology, see Axtell (1997).

7 For some of the key defences of robust virtue epistemology, see Sosa (1988; 1991; 2007; 2009), Zagzebski (1996; 1999), and Greco (2010). Note that each of these proposals incorporates a different account of how one should unpack the 'because of' relation in play here. See also endnotes 5 and 6 .

8 While the idea that a lucky event is an event which could very easily have not obtained is widely endorsed in the literature, it is not completely uncontroversial. It would take us too far afield to defend this claim here, however. For discussion of how best to think of lucky events, and for further defence of this particular account of lucky events, see Pritchard (2005, ch. 5; 2013; forthcomingb). See also Pritchard \& Smith (2004).

9 This is certainly true, for example, of the cases cited in the original article-see Gettier (1963).

10 This Gettier-style case was originally due to Chisholm $(1977,105)$.

11 The distinction between intervening and environmental luck (and thus between intervening and environmental epistemic luck) is due to Pritchard (2009a, chs. 3-4; 2009b; 2012a). See also Pritchard, Millar \& Haddock (2010, chs. 2-4) and Kallestrup \& Pritchard (2011; 2012; 2013).

12 In making this claim it is important, of course, to keep the details of the case fixed. That one is trying to hit a bull's-eye in conditions where there are potentially freak winds in play is different from aiming for this same goal in normal conditions, and so requires different abilities. But we are talking about an agent aiming for the bull's-eye in otherwise normal conditions who is (unbeknownst to them) subject to possible freak winds, which don't in fact materialize. Our claim is that two counterparts, both possessing the same degree of ability, and in the same actual circumstances, will both exhibit achievements to the same extent, even if one of the agents happens to be in an environment in which circumstances could have been unfavourable for that achievement, but in fact weren't. We take this claim to be intuitive, but for a thorough argument for this claim, see Kallestrup \& Pritchard (2011). 13 This claim about knowledge is usually understood as the thesis that knowledge demands safety. See Luper (1984; 2006), Sainsbury (1997), Sosa (1999), Williamson (2000), and Pritchard (2002; 2005; 2007; 2012a; 2012b). For a comprehensive and up-to-date discussion of the merits of the safety condition for knowledge, see the exchange between Pritchard (2013) and Hetherington (2013).

14 Of course, if one is persuaded by robust virtue epistemology, then one might be tempted to deny that knowledge requires safety. This is in fact just the route taken by Sosa (e.g., 2007, ch. 5), though it is obviously not a cost-free response to the problem in hand. For specific discussion of Sosa's proposal in this regard, see Pritchard (2009a). 15 For further discussion of the challenge posed to robust virtue epistemology by testimonial knowledge, see Kallestrup \& Pritchard (2012).

16 Elsewhere, one of the authors of this paper has described this phenomenon as the epistemic dependence of knowledge, where this has both a negative and a positive aspect. See Kallestrup \& Pritchard (2013).

17 It is helpful here to apply the 'past-self' test. Were Campbell to learn that there were plausible fake fire officers nearby, would he thus regard his former self as failing to understand why his house burnt down, given that he is aware that the person he asked was a genuine fire officer? Surely not. (And yet he surely would regard his past self as lacking propositional knowledge of why his house burned down).

18 For a more detailed discussion of the relationship between propositional knowledge and understanding-why, see Pritchard (2009b), Pritchard, Millar \& Haddock (2010, ch. 4), and Carter \& Pritchard (2013). See also Grimm (2006) and the exchange between Pritchard (forthcominga) and Grimm (forthcoming). 
19 Indeed, try applying the 'past-self' test here (see endnote 17). If Campbell were to subsequently discover that his belief about how his house burned down was only true as a matter of luck in this way, then he surely would not regard his past self as knowing why his house burned down.

20 See Carter \& Pritchard (2013).

21 As we explain in Carter \& Pritchard $(2013, \$ 1)$.

22 For more on this point, see Carter \& Pritchard (2013).

23 Applying here the 'past self' test (see endnotes 17 and 19), if Charlie were to subsequently discover that he gained his beliefs about the right way to change a light bulb from a genuine authoritative light bulb changing guide (albeit one which could have easily been a fake), wouldn't he nonetheless regard his former self as having known how to change a light bulb?

${ }^{24}$ It is worth reiterating that we are not, as Poston seems to be, equating cognitive ability with intelligence. We have a more specific notion of cognitive ability in mind which is standard fare in virtue epistemology (see endnote 6). It is worth noting, though, how we see the notion of intelligence fitting in. The story we have to tell here is a general one. Ryle (1946; 1949) originally defended anti-intellectualism in the context of attempting to explain intelligent action. An action has intelligence properties for Ryle in virtue of being guided by knowledge-how (a point the intellectualist can agree with). But, then, what is involved in possessing knowledge-how? The question we are addressing is thus a question the answer to which serves as part of an explanation for intelligent action.

25 Poston's (2009) argument has two premises, which Stanley neatly sums up as follows:

"(P1) Gettier cases for know how, if they exist, require that the subject intelligently and successfully F, where F ranges over actions; (P2) If one can intelligently and successfully F, then one knows how to F." (Stanley 2011b, 177)

26 This amendment, that in cases of knowledge-how the intelligence and success element be connected in the way we propose, helps to block a worry Stanley has proposed to Poston's contention that if one can intelligently and successfully F, then one knows how to F. Stanley $(2011$ b , 178) appeals to Bengson, Moffet \& Wright's (2009) case of Irina, a figure skater who has a neurological abnormality that causes her to 'act in ways that differ dramatically from how she actually thinks she is acting' and, despite the fact she is seriously mistaken about how to perform the Salchow jump, performs (due to the abnormality) the correct sequences of moves so that she successfully performs the Salchow (Bengson, Moffet $\&$ Wright 2009, 138; Stanley 2011b, 178). Two points should be noted about this case. For one thing, it's not clear that Stanley's appeal to it is effective in objecting to Poston's original contention that if one can intelligently and successfully $\mathrm{F}$, then one knows how to F. This is because it's not at all obvious that Irina is performing the Salchow intelligently. But even if we grant Stanley that she is performing the Salchow intelligently, the fact that she performs the correct sequence of moves is due more to her neurological abnormality than to her intelligence, and so Stanley couldn't appeal to this case to undercut our amended version of Poston's account, according to which one knows how to $\mathrm{F}$ just in case one can successfully $\mathrm{F}$ because of one's intelligence (visà-vis $\mathrm{F}$ ).

${ }^{27}$ It is important to emphasise here that the relevant success element in the view we are proposing is not merely the acquisition of a true belief; if it were, it would be tempting to view our proposal as a kind of intellectualism. Rather, the success element is a kind of outcome; in the case of riding a bike, the success element will be moving one's arms and legs in a particular way that counts as successfully riding a bike. We are open to the possibility that what counts as riding a bike (and, hence, what counts as satisfying the success condition) might be more demanding in some contexts than in others.

28 We are grateful to Jesús Navarro Reyes for detailed comments. Thanks also to Yuri Cath, Ted Poston, Jason Stanley, and Cheng-Hung Tsai for helpful discussion. 